\title{
COMMUNITY AND CONSUMER PARTICIPATION IN HEALTH
}

\section{Louise McMeeking and Michael von Kolpakow Consumer and Community Development Branch NSW Department of Health}

The benefits of consumer involvement in decisions about their health care have long been acknowledged. Consumers and community members have been involved in the public health system through advisory committees and as volunteers, and their participation is reflected in NSW Government policy including NSW health policy.

Health services use a range of strategies to inform and involve consumers in decision-making in the health system. While there is always room for improvement, there are many examples of good things happening in the area; some of these are described here.

Fifteen area health services currently have formal structures for ongoing community participation. These structures are variously called health councils, health consumer networks, consumer and community health forums, and consultative committees. The role and activities undertaken vary and include local needs assessment, input to planning, and health promotion activities. The two area health services without an arealevel structure for community participation are in metropolitan Sydney; however, plans are in place to ensure consumer involvement in these areas.

In March 2000, the Minister for Health announced the Government Action Plan, following consideration of the recommendations of the Report of the NSW Health Council and the Report from the Ministerial Advisory Committee on Smaller Towns (The Sinclair Report). A component of the Government Action Plan was the involvement of people who directly use health services, their families or carers, organisations with an interest in the health system, and the residents of NSW, in the decisions made in the health system.

In early 2000, the Consumer and Community Participation Implementation Group (CCPIG) was established. With input from a wide range of individuals and community groups, this group looked at ways for people to:

- get better access to information about health and health services;
- participate in decisions about their local health services;

- influence decisions about how the health system operates on a statewide basis.

The CCPIG's final report Partners in Health Report was released in November 2001. It provides a framework and direction for consumer and community participation in NSW Health.

In response to the report, the Minister for Health announced the establishment of the Health Participation Council, a ministerial advisory committee appointed for a period of two years. The Council's membership includes nominees of consumer and community organisations and a small number of health service staff. The first meeting was held in March 2002 and meetings are bi-monthly.

In addition, a new branch has been established within the NSW Department of Health, to foster participation throughout the health system. The Consumer and Community Development Branch commenced in January 2002.

Consumer forums have proven valuable for networking and for providing opportunities for consumers to be informed of the current work in both the Department and the area health services. Forums were held in November 1999, March 2001, and October 2002 and were attended by consumer representatives from each area health service, health-related non-government organisations, and selfhelp groups. Rural area health services are provided with grants to assist with travel expenses.

NSW Health continues to work towards the goal identified in the Partners in Health Report: 'to offer everyone in NSW, wherever they live and whatever special language or other needs they may have, equal access to opportunities to participate in health decision making to obtain the information they need to improve their own and their community's health.'

Further information on consumer and community participation in health visit can be obtained from the website at www.health.nsw.gov.au/policy/ participate. 